\title{
A música urbana de Luís Gonzaga
}

Braulio Tavares*

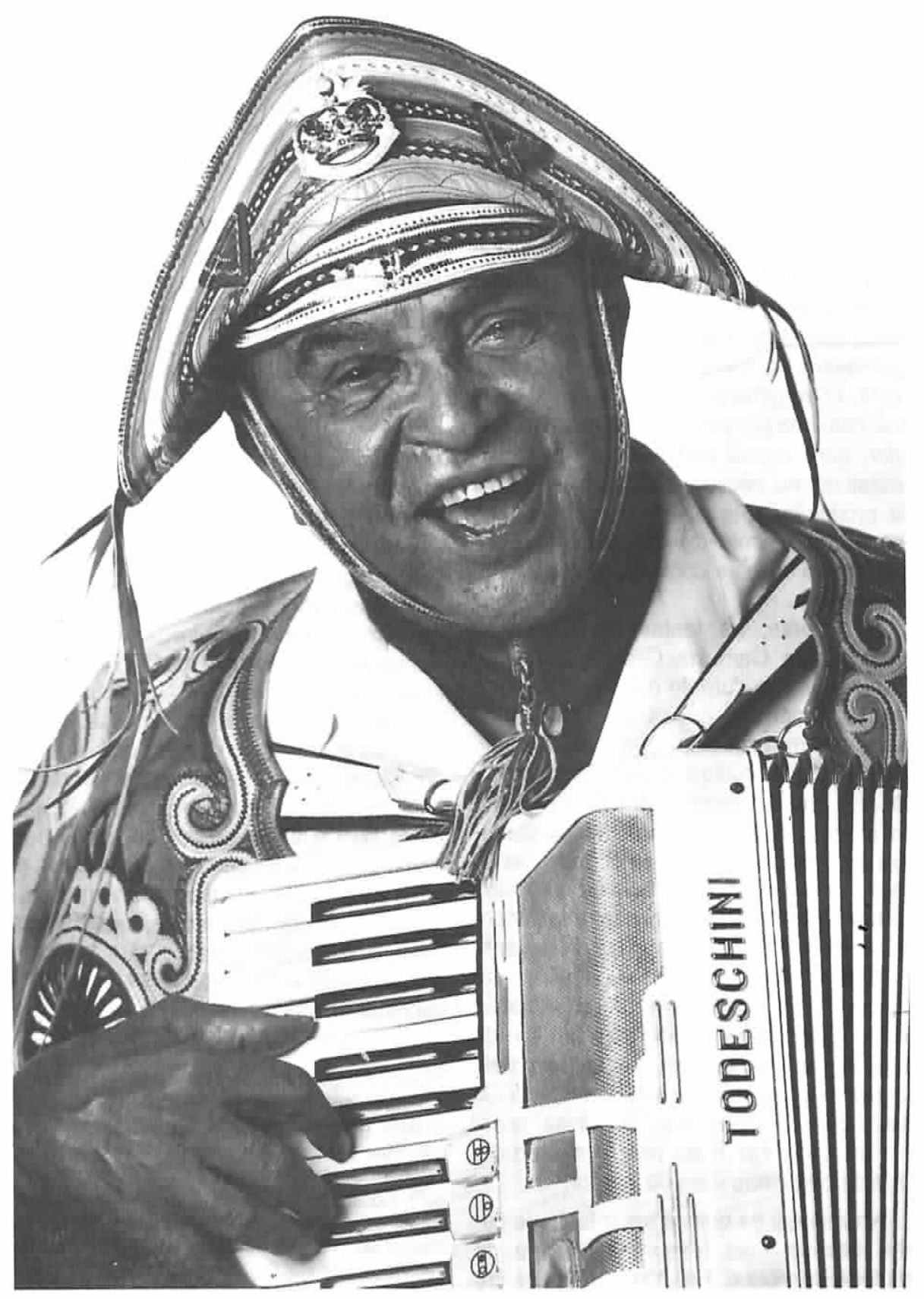

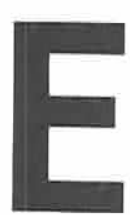

xistem alguns equivocos que cercam a obra de Luís Gonzaga. Nāo no que se refere à importância dessa obra, que, mesmo com fases crescentes e minguantes, sempre mereceu respeito por parte da crítica musical brasileira; mas há equivocos de interpretação, que decorrem da pouca informação que se tem sobre o Nordeste, geralmente enxergado através de estereótipos, simplificaçōes, caricaturas precárias.

Luís Gonzaga é conhecido no Rio e Sāo Paulo como um típico representante da música rural - quando sua música é rural apenas na temática, mas em espirito é essencialmente urbana. Costuma-se dizer que o baião é um gênero da música nordestina - mas ninguém diz que ele foi inventado no Rio de Janeiro. As músicas de Gonzaga são muitas vezes classificadas na Imprensa como "o legítimo forró tradicional do Nordeste", quando na realidade o forró tradicional era algo muito diferente, e foi "modemizado" por Gonzaga para que este pudesse abrir espaço dentro de um mercado musical que tinha seus próprios estatutos.

Comecemos por este último aspecto. Nascido em 1912, Gonzaga aprendeu a tocar com seu pai, o velho Januário, cujo fole-de-oito-baixos animava os forrós da zona rural de Exu. Será que os forrós tocados por Januário nessa época eram semelhantes aos que Luis, trinta anos depois, iria tornar conhecidos pelo Brasil inteiro? Duvido muito. Em primeiro lugar: o forró de 1912 era uma música instrumental, feita para dançar. Certamente não tinha partes cantadas, e se as tinha era de modo incidental, talvez uma inserção ocasional de aboios-em-sextilhas ou de cantigas tradicionais. A letra era quase ausente. No que se refere à música feita para dançar, a canção-com-letra-e-música é um 
estágio posterior, mais complexo, em relação à música instrumental.

Os forrós de Januário eram certamente à base de fole e da percussão disponivel (foi Luis que, depois, acabou consagrando o esquema sanfona-zabumba-triângulo). A parte cantada, se havia, era insignificante (aliás, poucos indivíduos conseguiriam, como Luís, cantar mais alto do que a sanfona). O próprio Luís, quando começou a forçar a porta do mercado radiofônico do Rio, foi com o material mais característico que tinha: um número instrumental (Vira e Mexe, 1941). So depois que "acertou os ponteiros" com Humberto Teixeira foi que nasceu a idéla de fazer um "forró com letra"; e isso significou a criação do baião. Isso não quer dizer que o baião foi criado do Nada, mas apenas que se considera uma coisa "criada" depois que é veiculada oficialmente, e atribui-se sua criação a quem a veiculou.

Passamos ao ponto seguinte: 0 baiāo foi inventado no Nordeste ou no Rio de Janeiro? Não interessa vasculhar a biografia de Gonzaga para procurar algo tipo "Foi numa madrugada chuvosa de 1937 que eu peguei a sanfona sem nem saber que naquela noite iria acabar inventando o baião..." Não é assim que as coisas acontecem. A minha especulação pessoal (corrijam-me se eu disser algo absurdo) é a de que Gonzaga, no Rio, tinha em seu repertório instrumental um imenso número de xaxados, xamegos, xenhenhéns e outros ritmos instrumentais-dançantes do Nordeste. Conheceu Humberto Teixeira -um advogado culto e letrado, que lhe propôs cançōes com temática nordestina (ou seja, algo que năo tinha nada a ver com as tendências musicais da época). Ao ouvir falar em cançōes do tipo letra-e-música, Gonzaga lembrou-se dos cantadores de viola e do ponteio característico que servia de acompanhamento aos seus versos (ton, ton-don... ton, ton-don...). Era um toque mais lento, mais cadenciado, mais favorável ao canto - diferentemente de melodias frenéticas como Vira e Mexe, quase impossivel de cantar. Usando um "baião" desse tipo como base musical, e colocando ali uma melodia singela, não seria difícil sair engastando, silaba por silaba, os poemas de Humberto Teixeira. Encarando a coisa sob esse ponto de vista, 0 baiăo não é uma música autenticamente sertaneja que chegou ao Rio: é o resultado do trabalho de dois sertanejos aculturados, tentando produzir, dentro do mercado musical carioca, um tipo de música que fosse uma sintese de suas raizes culturais $e$ ao mesmo tempo fosse algo razoavelmente novo.

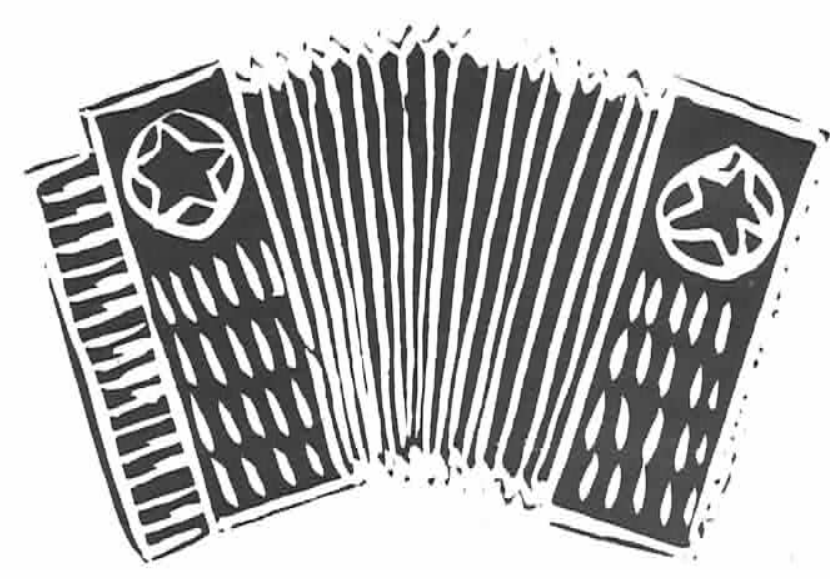

Vem daí a minha afirmativa de que o baião, vendido como música rural, é uma música essencialmente urbana. Somente na aceleração cultural produzida por um ambiente urbano seria possivel forçar esta sintese: forró-dançante-instrumental + ponteio-de-acompanhamento-dos-violeiros + cando + poesia. Em espírito, o baião é uma música urbana: sua temática é que é rural. O baiăo, na forma como se consagrou, não é uma música de nordestino-noNordeste: é uma verdadeira canção-deexilio. Foi al que eu vim mimbora carregando a minha dor. Lá no meu pé de serra deixei ficar meu coraçăo. Quando eu vim do sertão, seu moço, do meu Bodocó. Hoje longe muitas léguas, na mais triste solidão. Fosse o parceiro Humberto Teixeira ou Zédantas, o sentimento transmitido era o de Gonzaga: o do caboclo simples que deixa a terra natal, conquista a cidade grande, e começa a cantar uma saudade poética que acaba se tornando saudade real: ela retorna famoso ao Nordeste ("Quando eu voltei lá pro sertão, eu quis mangar de Januário com meu fole prateado...") mas percebe que para reencontrar o lugar de origem não basta retomar geograficamente. A grande desilusăo do migrante é quando ele entende que uma viagem no espaço é também uma viagem no tempo, e que quando se retorna para a terra natal é apenas para constatar que ela também mudou, e que é impossivel alguém voltar para o mesmo lugar de onde saiu.

Pode-se dizer, entāo, que Luís Gonzaga é a primeira fase da urbanizaçăo da música nordestina. A segunda fase seria caracterizada mais tipicamente pelo trabalho de Jackson do Pandeiro - o nordestino já integrado no meio urbano, trocando o chapéu de vaqueiro pelo chapeuzinhopreto-com-pena-na-fita, incorporando o samba com coragem e com jogo de cintura, falando mais do Campo de São Cristóvāo do que do Pajeú. E a terceira fase se- ria a da chegada dos cantores/compositores oriundos da classe média nordestina (Alceu Valença, Fagner, Zé Ramalho, Geraldo Azevedo, Belchior, Ednardo), que viriam trazer outras propostas em termos de letra e de música, embora sempre reconhecendo sua divida para com Gonzaga.

Talvez o tipo de canção criado por Luís Gonzaga e seus parceiros seja um dos melhores exemplos de música de desenraizamento, de cantiga urbana criada pelos exilados do mundo rural. O baião inventado por Luls Gonzaga deu aos cariocas, nos anos 40, a impressão de estar diante de um tipo de música primitivo, rude e autêntico, brotado das brenhas agrestes do sertão. O fato de Gonzaga ter iniciado sua carreira vestindo gibăo de couro e chapéu de vaqueiro reforçava essa idéia, mas isso era simples jogo-de-cena: uma concessão meio ridícula mas que às vezes o sujeito faz - algo como se Paulinho da Viola fosse fazer um show na França e tivesse que subir ao palco vestido de Mestre-Sala de Escola de Samba. O que os cariocas não sabiam é que esse baião, longe de ser um produto "rude e bravio" da cultura sertaneja, tinha sido amadurecido ao longo das noites em que Gonzaga to'cava sanfona na zona do Cais do Porto, interpretando In the Mood para marujos americanos, depois descansando numa valsa, e talvez pensando: "Minha Nossa Senhora, será que eu vou ter que ficar tocando esses troços até o fim da vida?".

Não teve,

"Poeta, compositor e jomalista. Ex-organizador do "Congresso Nacional de Violeiros" de Campina Grande (Paralba) de 1975 a 1979. Tem músicas gravadas por Elba Ramalho ("Nordeste Independente", "Caldeirăo dos Mitos", "A Roda do Tempo"). Reside no Rio de Janeiro. Publicou recentemente o livro "A Espinha Dorsal da Memória", ganhador do "Prêmio Caminho de Fioçáo-Cientficica 1989", da Editorial Caminho, de Lisboa. 